\title{
Self-Esteem and Direct Versus Indirect Forms of Self-Enhancement
}

\author{
Jonathon D. Brown \\ Southern Methodist University
}

\author{
Rebecca L. Collins and Greg W. Schmidt \\ University of California, Los Angeles
}

\begin{abstract}
Two studies explored the relation between self-esteem and self-enhancement biases. It was proposed that people with high self-esteem engage in forms of self-enhancement in which the self is directly linked to positive identities and outcomes, whereas people with low self-esteem engage in forms of self-enhancement in which the self is indirectly linked to positive identities and outcomes. To test the hypothesis, we examined group favoritism as a function of self-esteem and group involvement. As expected, high self-esteem subjects were most apt to display favoritism when they were directly involved in group processes, whereas low self-esteem subjects were most apt to display favoritism when they were not directly involved in group processes. Furthermore, consistent with the view that these tendencies reflect a motivated desire to enhance self-worth, these effects were less evident after subjects had received positive feedback than after they had received negative feedback. The discussion centers on the nature of high and low self-esteem and the influence of self-enhancement and self-consistency motives in social behavior.
\end{abstract}

Conventional wisdom holds that self-serving biases are principally the refuge of those with low self-esteem. This position, typically referred to as self-enhancement theory (Shrauger, 1975), is based on the notion that all individuals are motivated to maintain a positive self-concept, and that the need for selfenhancement increases the more the desire to think favorably of the self goes unfulfilled. In their efforts to shore up a negative self-image, those with low self-esteem are presumed to distort and bias personal information in a self-enhancing direction (cf. Dittes, 1959; Jones, 1973; Kaplan, 1975).

In contrast to the preceding view, which holds that self-enhancement biases are more prevalent among those with low self-esteem than among those with high self-esteem, other theories suggest that individuals with high self-esteem are more apt to display evidence of self-enhancement. Self-consistency theorists (Lecky, 1945; Swann, 1983, 1987) contend that individuals are motivated to maintain a consistent self-image because stable self-views enable them to predict and control their world (Epstein, 1973). From this perspective, people with high selfesteem more than those with low self-esteem should exhibit selfenhancing biases, because such biases strengthen the self-image of those with positive self-views but threaten the self-image of those with negative self-views.

Despite the theoretical elegance of each of these arguments, recent research has failed to distinguish consistently between these opposing views (McFarlin \& Blascovich, 1981; Swann, Griffin, Predmore, \& Gaines, 1987). Under some conditions and with some dependent variables, people with low self-esteem

This research and preparation of this article were supported by a New Faculty Seed Grant from Southern Methodist University to Jonathon D. Brown.

We thank Bill Swann and Shelley Taylor for their helpful comments on a previous version of this article.

Correspondence concerning this article should be addressed to Jonathon D. Brown, Department of Psychology, Southern Methodist University, Dallas, Texas 75275-0442. appear more self-aggrandizing than do those with high self-esteem; under other conditions and with other dependent measures, the reverse is true. This has elicited calls to abandon the "either-or" approach that has characterized prior research in favor of a more integrative view (Rosenberg, 1979; Shrauger, 1975; Swann et al., 1987). The purpose of this article is to contribute to such an integration.

\section{The Present Model}

One possible point of departure toward reconciling the two theories is to propose that both those with high and those with low self-esteem seek self-enhancement, but do so in different ways. More formally, we speculate that although the strength of the motive to enhance self-worth may not vary as a function of chronic levels of self-esteem, important differences exist with respect to the means whereby those with high and those with low self-esteem seek self-enhancement. In the sections that follow, we elaborate on the reasoning behind these assertions.

As concerns the first part of our thesis, a great number of scholars have argued that the desire to achieve a positive selfimage is a universal human motivation. This motive, which McDougall (1932) referred to as the master sentiment, has been endorsed as a principal force of human behavior by philosophers (e.g., Hobbes, Kant, Nietzsche, and Rosseau), cultural anthropologists (e.g., Becker), and sociologists (e.g., Rosenberg), as well as numerous theorists from psychiatry and psychology (e.g., Adler, Allport, Horney, James, Koffka, Rogers, and Sullivan). The conclusion that each of these students of human behavior has converged on was perhaps best stated by Pulitzer Prize-winning anthropologist Ernest Becker, who wrote:

The fundamental datum for our science is a fact that at first seems banal, or irrelevant: it is the fact that-as far as we can tell-all organisms like to "feel good" about themselves. . . . Thus in the most brief and direct manner, we have a law of human development, ... the Principle of Self-Esteem Maintenance. (Becker, 1968 , p. 328) 
A motivation to enhance self-worth does not, however, ensure that a positive identity will be realized. That is, although individuals may prefer to "think as well of themselves as they can get away with" (Smith, 1968, p. 368), what they can get away with is limited by (a) private self-perceptions, (b) beliefs about what others will accept, and (c) objective evidence in the environment (Pyszczynski \& Greenberg, 1987; Schlenker, 1985). An individual who lays claim to having superior athletic prowess, for example, may someday be called on to demonstrate this skill to both self and others. Thus, in order to be effective, desirable images of the self must be perceived as believable and grounded in social reality.

In the present view, it is this aspect of social life that accounts for differences in the ways in which people with high and people with low self-esteem seek to promote a positive self-image. Those with low self-esteem, almost by definition, doubt their competence in many areas. Consequently, their pursuit of selfaggrandizement is likely to be impeded by concerns that a positive identity can successfully be defended. In contrast, people with high self-esteem are confident of their abilities. Hence, they are relatively unfettered by such concerns and further efforts at promoting self-esteem can proceed relatively unobstructed.

\section{Direct Versus Indirect Forms of Self-Enhancement}

Because they face disparate demands, those with low self-esteem may engage in different forms of self-enhancement than do those with high self-esteem (cf. Baumeister \& Tice, 1985). In particular, we propose that people with high self-esteem tend to engage in direct forms of self-enhancement, whereas those with low self-esteem tend to bolster self-worth indirectly. As used here, the difference between these terms concerns the degree to which the self is directly implicated in esteem-enhancing biases. With direct self-enhancement, the self is directly linked to positive identities and outcomes; with indirect self-enhancement, the self is only indirectly linked to positive identities and outcomes by virtue of one's association with others. In other words, direct self-enhancement occurs when individuals exhibit esteem-enhancing biases that explicitly center around the self, whereas indirect self-enhancement occurs when individuals exhibit esteem-enhancing biases that involve other members of the social world.

Some research examples serve to clarify further the distinction we have made between direct and indirect forms of selfenhancement. An example of direct self-enhancement is provided by research that has examined individuals' evaluations of self and others. Numerous studies have found that individuals display a pronounced self-other bias such that desirable personality attributes are seen as more descriptive of the self than of others, but undesirable personality attributes are seen as less descriptive of the self than of others (e.g., Alicke, 1985; Brown, 1986; Rosenberg, 1979). Evaluating the self in more positive and less negative terms than one appraises other members of the social world constitutes a direct form of self-enhancement insofar as individuals are directly laying claim to superior status for the self. The tendency for individuals to accept greater responsibility for success than failure is another example of direct self-enhancement, as this biased attributional pattern involves outcomes for which the individual is personally responsible.

But directly linking the self to positive identities and outcomes is not the only way individuals can attempt to enhance self-esteem; one's relationships with others may also be used to promote feelings of personal worth (Tesser \& Campbell, 1982). For instance, individuals can bask in the reflected glory of others' accomplishments by emphasizing their association with them (Cialdini et al., 1976). To illustrate, Cialdini et al. found that university students were more likely to use the pronoun we when relating the details of a football game their team had won than when describing a game their team had lost (see also Cialdini \& Richardson, 1980; Snyder, Lassegard, \& Ford, 1986). Basking in reflected glory represents an indirect form of selfenhancement insofar as individuals have played no direct role in attaining the outcome for which they are assuming credit. Instead, self-enhancement occurs in a more roundabout way as individuals attempt to align themselves with successful others (or distance themselves from unsuccessful others).

To our knowledge, the relation between chronic levels of selfesteem and a preference for direct versus indirect self-enhancement strategies has not been explored in prior research. As noted earlier, however, there is reason to believe that people with high self-esteem will favor direct self-enhancement, whereas those with low self-esteem will favor indirect self-enhancement. Consider first the predictions for those with high self-esteem. Because they have generally positive self-conceptions, esteemenhancing illusions that directly implicate the self are largely believable to those with high self-esteem. Consequently, people with high self-esteem should avail themselves of the direct route to esteem enhancement. In contrast, those with low self-esteem are plagued by doubts regarding their self-worth. As a result, esteem-enhancing illusions that directly implicate the self are not believable to these individuals, and they are unlikely to engage in direct forms of self-enhancement. Instead, those with low self-esteem should be more apt to display evidence of indirect self-enhancement.

\section{Summary}

To summarize, it has been contended that (a) all individuals experience a strong desire to enhance self-worth, but (b) people with low self-esteem are more constrained in their pursuit of this goal by concerns that a positive self-image can be defended. Consequently, the specific form self-enhancing behaviors take differs among those with high and those with low self-esteem: Whereas people with high self-esteem tend to engage in direct forms of self-enhancement, those with low self-esteem are more prone to bolster self-worth indirectly.

\section{Study 1}

To test the preceding hypothesis, we examined the effects of self-esteem and group involvement on group favoritism. Prior research has shown that when individuals are placed into groups on an arbitrary basis, in-group members receive greater rewards and are evaluated more favorably than are out-group members (for a review, see Brewer, 1979). A number of theorists 
have attributed this tendency to a motivation to enhance selfworth (e.g., Tajfel \& Turner, 1986; Wills, 1981).

Whether this effect is stronger among people with high selfesteem than among those with low self-esteem is somewhat unclear, however (Crocker \& Schwartz, 1985; Crocker, Thompson, McGraw, \& Ingerman, 1987). From the present perspective, the influence of self-esteem on group favoritism should depend on the degree to which individuals are active group members. When individuals are actively involved in group processes, favoritism represents a form of direct self-enhancement; when individuals are not actively involved in group processes, favoritism represents an indirect form of self-enhancement. Thus, on the basis of the preceding analysis, we can predict that people with high self-esteem will be more apt to exhibit group favoritism under the former condition than the latter, whereas people with low self-esteem will be more inclined to display favoritism under the latter condition than the former. These hypotheses were tested in Study 1.

\section{Method}

Overview. In the first part of the experiment, a dot-estimation task (Gerard \& Hoyt, 1974) was used to divide subjects arbitrarily into two groups. The underestimators were those who allegedly had underestimated the number of dots in a series of stimulus displays, and the overestimators were those who allegedly had overestimated the number of dots in a series of stimulus displays. Following the delivery of these manipulations, one half of the underestimators and one half of the overestimators were taken to a different experimental room. All four groups (i.e., two groups of underestimators and two groups of overestimators) then completed a brief group problem-solving task. After completing the task, two experimental conditions were created. Subjects in the own-groupout-group condition were asked to compare the merits of their own group's solution (i.e., the solution created by the group in which they participated) with a solution created by an out-group. Those in the ingroup-out-group condition were asked to compare the merits of their fellow in-group's solution (i.e., the solution created by a group of the same label but not the group in which the subjects participated) with that of an out-group. In this manner, subjects in the own-group-outgroup condition were evaluating a product they had helped create, whereas those in the in-group-out-group condition were evaluating a product they had not had a hand in creating, but one that their counterpart in-group members in the adjacent experimental room had created. A positive discrepancy between own-group and out-group products represents direct self-enhancement, whereas a positive discrepancy between in-group and out-group products represents indirect self-enhancement.

Subjects. The subjects were 11 male and 51 female undergraduates enrolled in introductory psychology courses at the University of California, Los Angeles (UCLA). Subjects participated in groups of 13 to 18 people and received partial credit toward a course requirement in exchange for their participation. Two subjects failed to complete all of the stimulus materials, leaving a final sample of 60 subjects.

Materials and procedure. At the outset of the study subjects were greeted by a male and a female experimenter and asked to sign a standard informed consent form. Subsequently, in an effort to facilitate honest responding, subjects were given a code number and told that they should not put their names on any of the other questionnaires they would be completing.

The dot-estimation task was then introduced, adapting instructions developed by Gerard and Hoyt (1974). Subjects were told that prior research had established that when given the task of estimating the number of objects they have seen, different people tend to consistently over- estimate or underestimate the correct number. Subjects were further informed that although psychologists allegedly placed no value on whether it was better to be an overestimator or an underestimator, individuals who underestimate tend to be similar to one another in other ways, just as those who overestimate tend to share a number of other characteristics.

A form with five blanks was then distributed. For each of five trials, the experimenter held up a large piece of white cardboard covered with a number of dots for $3 \mathrm{~s}$, and subjects recorded their estimates in the spaces provided. Following the five presentations, the forms were collected and the experimenter announced that "While I am scoring these, the other experimenter will be taking over." Experimenter A then went into an adjoining room with subjects' dot-estimation forms.

Experimenter B then passed out the Texas Social Behavior Inventory (TSBI; Helmreich \& Stapp, 1974). The TSBI is a well-validated measure that places particular emphasis on the social aspects of self-esteem (see Helmreich \& Stapp, 1974, for information regarding the scale's psychometric properties). The internal consistency of the TSBI in the present sample was high $(\alpha=.86)$.

Shortly after subjects completed the TSBI, Experimenter A returned from the adjacent room and announced that she had gone through their responses to the dot-estimation task and had divided subjects into two groups: those who tended to consistently overestimate the correct number of dots and those who tended to consistently underestimate the correct number of dots. (In fact, group assignment was random.) She then proceeded to list subjects' code numbers on a blackboard under the headings "Overestimators" and "Underestimators".

At this point, approximately half of the overestimators and half of the underestimators were instructed to follow Experimenter B into the adjoining room; the remaining subjects were told to stay with Experimenter $\mathrm{A}$ in the main experimental room. In each room, subjects were given group badges that proclaimed their group label, and were seated around separate tables according to their group classification (group sizes ranged from 3 to 5 people). They were then informed that in order to investigate the effects of overestimation and underestimation on creativity they would participate in a group brainstorming task (Dion, 1979). After appointing 1 subject in each group to serve as the group secretary, the groups were given $4 \mathrm{~min}$ to think of as many unusual uses as they could for a flyswatter.

At the conclusion of the brainstorming task, the experimenters collected each group's solutions and distributed a questionnaire that assessed attitudes toward the group. These items asked subjects to rate how much they (a) had enjoyed working in the group, (b) liked the other group members, (c) felt similar to the other group members, and (d) were interested in working with the group in the future. Responses to these queries were made on 7-point scales $(1=$ not at all; $7=$ very much $)$.

While subjects were completing the posttask questionnaire, the experimenters met in the hallway and randomly chose the lists from one room to be used for the evaluation task. The first 5 nonoverlapping items appearing on the selected lists were identified. Subsequently, the experimenters returned to their respective rooms and informed subjects that because they needed some means of determining how creative the groups had been, subjects were being asked to evaluate some of the lists.

Each experimenter then posted the five selected solutions to the group task under appropriate group headings, explaining to subjects how the five items had been selected and whether the lists had been generated by the subjects in that room (own-group-out-group condition) or by subjects in the adjoining room (in-group-out-group condition). Two rating forms were then distributed, and subjects were instructed to rate how interesting, creative, original, imaginative, and clever they thought each group's solution was by using 11 -point rating scales $(0=$ not at all; $10=v e r y$ ). Approximately half of the subjects first evaluated us (i.e., either own-group or in-group), then them (i.e., either out-group in the same room or out-group in the adjoining room), whereas the order was 
Table 1

Mean Evaluation Ratings for Us and Them as a Function of Experimental Condition and Self-Esteem

\begin{tabular}{lcccccc}
\hline & \multicolumn{2}{c}{ High self-esteem } & & \multicolumn{2}{c}{ Low self-esteem } \\
\cline { 2 - 3 } Condition & Us & Them & & Us & Them \\
\hline Own-group-Out-group & & & & \\
$M$ & 8.68 & 5.92 & & 6.95 & 7.10 \\
$S D$ & 1.04 & 1.76 & & 1.36 & 1.77 \\
$N$ & 12 & 92 & & 13 & 42 \\
In-group-Out-group & & & & \\
$M$ & 6.59 & 6.15 & & 5.92 & 4.70 \\
$S D$ & 1.55 & 1.89 & & 1.38 & 1.66 \\
$N$ & 10 & 50 & & 16 & 80 \\
\hline
\end{tabular}

Note. Proportions of subjects showing favoritism are presented in italics.

reversed for the remaining subjects. After completing their evaluations, the rating forms were collected and subjects regrouped in the main experimental room where they were debriefed.

\section{Results}

Main analyses. An evaluation index for $u s$ and them was derived for each subject by averaging across the five items on the two evaluation questionnaires (for $u s, \alpha=.91$; for them, $\alpha=.93$ ). Preliminary analyses revealed no effects of gender or order of evaluation (i.e., us first or them first). Hence, these variables were ignored, and the data were submitted to a 2 (selfesteem: high or low) $\times 2$ (condition: own-group-out-group or in-group-out-group) $\times 2$ (target: $u$ s or them) unweighted means mixed analysis of variance (ANOVA), with the last factor treated as a within-subjects variable. ${ }^{1}$

Self-enhancement in the minimal group paradigm takes the form of a positive discrepancy between evaluations for $u s$ versus them. We expected that this favorability bias would be most evident among those with high self-esteem in the own-groupout-group condition, but most evident among those with low self-esteem in the in-group-out-group condition. Formally, these predictions translate into a three-way (Self-Esteem $X$ Condition $\times$ Target) interaction in the ANOVA.

Along with main effects for self-esteem, $F(1,47)=5.28, p<$ .05 , condition, $F(1,47)=20.79, p<.01$, and target, $F(1,47)=$ $9.52, p<.01$, the expected three-way interaction was significant, $F(1,47)=7.12, p=.01$. As shown in Table 1 , the form of the interaction was as predicted. Just as high self-esteem subjects showed greater favoritism in the own-group-out-group condition than in the in-group-out-group condition, low selfesteem subjects showed greater favoritism in the in-group-outgroup condition than in the own-group-out-group condition. Subsequent analyses confirmed that high self-esteem subjects gave higher ratings to us than them in the own-group-out-group condition, $t(47)=3.99, p<.01$, but not in the in-group-outgroup condition, $t<1$, whereas this pattern tended to be reversed among low self-esteem subjects, $t<1$ and $t(47)=1.77$, $p<.08$, respectively. ${ }^{2}$

Additional aspects of the data are also consistent with the experimental hypotheses. Although group favoritism can result from either an overevaluation of own-group or in-group products or a devaluation of out-group products, derogation of outgroup products would seem to represent a more indirect form of enhancement, as it does not directly implicate the self. ${ }^{3}$ Consequently, when exhibiting favoritism, subjects with high selfesteem should tend to show own-group enhancement, whereas those with low self-esteem should be more apt to display outgroup derogation.

The data presented in Table 1 reveal just such a pattern. High self-esteem subjects gave higher ratings to $u$ in the own-groupout-group condition than in the in-group-out-group condition, $t(47)=3.02, p<.01$, but ratings for them did not differ across conditions, $t<1$. Among those with low self-esteem, however, ratings for $u s$ did not differ across conditions, $t(47)=1.49, n s$, but ratings for them were lower in the in-group-out-group condition than in the own-group-out-group condition, $t(47)=$ $3.47, p<.01$. Thus, favoritism among high self-esteem subjects primarily took the form of enhanced ratings for one's own group, but favoritism among low self-esteem subjects primarily took the form of depressed ratings of out-groups. These findings offer further evidence that people with high self-esteem seek to enhance self-worth directly, whereas those with low self-esteem follow more indirect routes to self-enhancement. ${ }^{4}$

Ancillary analyses. After completing the brainstorming task, subjects indicated their attitudes toward the other group members. Scores on these items were highly correlated $(\alpha=.87$ ), and an attraction index was formed by averaging across the four attitude items. An ANOVA on these scores revealed that subjects with high self-esteem expressed more favorable attitudes to-

\footnotetext{
${ }^{1}$ The median score on the Texas Social Behavior Inventory (TSBI) was 58.5. To avoid misclassifying subjects, individuals scoring within one-half point of the median (i.e., 58 or 59) were deleted from all statistical analyses. This left 22 subjects classified as low in self-esteem $(M=$ $47.59)$ and 29 subjects classified as high in self-esteem $(M=64.38)$. A Self-Esteem $\times$ Condition analysis of variance on subjects' TSBI scores revealed only the built-in main effect for self-esteem classification, $F(1$, $47)=85.94, p<.001$. Finally, it is important to note that the critical three-way interaction reported in the text remained significant when a median split on self-esteem scores was used, $F(1,56)=4.64, p<.05$.

${ }^{2}$ Because these mean values can be skewed by extreme ratings, we also examined the proportion of subjects in each condition who showed group favoritism (i.e., who gave higher ratings to $u$ s than to them). Following Langer and Abelson (1972), an arcsine transformation was performed prior to analyzing these data. As shown in Table 1, consistent with the earlier analyses on the rating scores, a greater proportion of high self-esteem subjects exhibited favoritism in the own-group-outgroup than in the in-group-out-group condition, whereas the reverse was true for those with low self-esteem, $Z=3.17, p<.001$.

${ }^{3}$ We are grateful to an anonymous reviewer for calling this point to our attention.

${ }^{4}$ Several additional analyses using the mean square error for the interaction $\left(M S_{\mathrm{e}}=2.95\right)$ revealed the following effects: A significant Condition $\times$ Target interaction for those with high self-esteem, $F(1,47)=$ $5.63, p<.05$, but not for those with low self-esteem, $F(1,47)=1.97$, ns; a significant Self-Esteem $\times$ Condition interaction for ratings for them, $F(1,47)=7.24, p<.025$, but not for ratings for $u s, F(1,47)=$ 1.18 , ns; a significant Self-Esteem $\times$ Target interaction in the owngroup-out-group condition, $F(1,47)=8.84, p<.01$, but not in the ingroup-out-group condition, $F<1$.
} 
ward the group $(M=5.48)$ than did subjects with low self-esteem $(M=4.76), F(1,47)=8.27, p<.01$.

To determine whether this tendency might account for the differential effects of self-esteem on favoritism, we first performed correlational analyses relating attraction scores to a favorability index (i.e., us minus them), both within each experimental condition and collapsed across conditions. None of the correlations reached statistical significance (all $p \mathrm{~s}>.20$ ). We also performed an analysis of covariance using attraction scores as a covariate. None of the effects reported in the preceding paragraphs was altered to an appreciable degree. Thus, the fact that high self-esteem subjects were more attracted to the group does not appear to account for the present findings.

\section{Discussion}

In sum, the data provide preliminary support for the hypothesis that people with high and people with low self-esteem seek self-enhancement in characteristic ways. In accordance with the hypothesis that people with high self-esteem engage in direct forms of self-enhancement, subjects with high self-esteem evaluated their own group's product more favorably than an outgroup's product. Moreover, the greater favoritism displayed by those with high self-esteem in the own-group-out-group condition than in the in-group-out-group condition was due to enhanced ratings for one's own group, rather than depressed ratings of out-groups. Both of these findings suggest that individuals with high self-esteem engage in forms of self-enhancement that directly implicate the self. High self-esteem subjects did not, however, display favoritism when they were not directly involved in the creation of the group's product. Although speculative, one reason why they may eschew indirect forms of selfenhancement is because such strategies are less efficient at enhancing self-worth.

In contrast to these effects, people with low self-esteem showed no evidence of favoritism when evaluating a product they had helped to create. To paraphrase Groucho Marx, these individuals appear to have been suspicious of any group that would have them as a member. Although reluctant to engage in direct forms of self-enhancement, those with low self-esteem were not entirely egalitarian in their product appraisals. Rather, these individuals showed a distinct tendency to favor the ingroup over an out-group. Furthermore, the greater favoritism displayed by those with low self-esteem in the in-group-outgroup condition than in the own-group-out-group condition was due to derogation of the out-group rather than enhancement of the in-group. Together, these findings suggest that those with low self-esteem seek to enhance self-worth indirectly by engaging in esteem-enhancing strategies that do not explicitly involve the self.

\section{Study 2}

We have argued that the results of Study 1 indicate that people with high and people with low self-esteem seek self-enhancement in different ways. A critical assumption underlying our interpretation of the data is that favoritism in the intergroup paradigm derives from a motivation to enhance self-worth. Although there is both theoretical and empirical support for this contention (e.g., Lemyre \& Smith, 1985; Tajfel \& Turner, 1986; Wills, 1981), thus far we have provided no evidence that this is the case.

One way to examine this issue is to assess the degree to which the effects observed in Study 1 are affected by temporary changes in self-esteem. Assuming that a motivated desire to enhance self-worth underlies group bias, favoritism should be less apparent when self-esteem has recently been bolstered than when it has recently been threatened (cf. Cialdini et al., 1976). If so, the following predictions can be derived: (a) People with high self-esteem will be less apt to engage in direct self-enhancement after receiving positive feedback than after receiving negative feedback; and (b) people with low self-esteem will be less apt to engage in indirect self-enhancement after receiving positive feedback than after receiving negative feedback. These hypotheses were tested in Study $2 .^{5}$

\section{Method}

Subjects. The subjects were 30 male and 81 female undergraduates enrolled in introductory psychology courses at UCLA. Subjects participated in exchange for course credit.

Materials and procedure. The same procedures used in Study 1 were followed in this study, with one exception. Instead of informing subjects that psychologists placed no value on whether it was better to be an overestimator or an underestimator, subjects were led to believe that prior research had established that it was better to be an overestimator (underestimator) than an underestimator (overestimator). Specifically, the following manipulation was delivered after subjects were divided randomly into two groups on the alleged basis of their dot-estimation tendencies.

Before we proceed with the rest of the experiment, let me tell you what psychologists have learned about overestimators and underestimators. Overestimators tend to be highly confident in their judgments and are not afraid to take chances. These individuals are able to see the broader issues of a problem and are therefore able to avoid getting bogged down in details. Underestimators, on the other hand, tend to be too conservative in their judgments and are afraid to take chances. These individuals tend to get bogged down in the specifics of a problem and are often unable to finish what they start. Thus, all in all, psychologists believe that it is better to be an overestimator than an underestimator.

For approximately one half of the subjects, the descriptions were reversed such that overestimators were portrayed as being too expansive in their thinking, whereas underestimators were characterized as being very precise in their thinking. In this case, subjects were told that psychologists believed it was better to be an underestimator than an overestimator.

\section{Results and Discussion}

Main analyses. As in Study 1, an evaluation index for $u$ and them was derived by averaging subjects' ratings on the five items on the evaluation questionnaires (for $u s, \alpha=.94$; for them, $\alpha=$ .91). Preliminary analyses again revealed no significant effects for gender or order of evaluation, and the subjects' scores were submitted to a 2 (self-esteem) $\times 2$ (condition) $\times 2$ (feedback) $\times$

\footnotetext{
${ }^{5}$ Studies 1 and 2 were run concurrently using independent samples from the same subject pool.
} 
2 (target) unweighted means mixed ANOVA, with the last variable treated as a within-subjects factor. ${ }^{6}$

We have argued that group favoritism in the minimal group paradigm stems from a desire to enhance feelings of personal worth. Therefore, we anticipated that the tendency for high selfesteem subjects to engage in direct self-enhancement and for low self-esteem subjects to engage in indirect self-enhancement would be less apparent after they had received positive rather than negative feedback. These predictions translate into a significant four-way interaction in the ANOVA.

Along with a main effect of condition, $F(1,87)=9.67, p<$ .01 , a marginal main effect of target, $F(1,87)=2.95, p<.10$, and Condition $\times$ Target and Feedback $\times$ Target interactions, $F(1,87)=4.07, p<.05$, and $F(1,87)=8.04, p<.01$, respectively, the ANOVA revealed the predicted four-way interaction, $F(1,87)=6.38, p=.01$. As each of the lower-order effects is qualified by the four-way interaction, our discussion is limited to the higher-order effect.

Separate Self-Esteem $\times$ Condition $\times$ Target ANOVAs were conducted within each feedback group to facilitate interpretation of the four-way interaction. A significant triple interaction of the form observed in Study 1 was found among subjects receiving negative feedback, $F(1,87)=5.58, p<.025$. Paralleling the results of the earlier study, the data displayed in the bottom half of Table 2 reveal that, following negative feedback, favoritism was greater among high self-esteem subjects in the owngroup-out-group condition than in the in-group-out-group condition, but greater among low self-esteem subjects in the latter condition than in the former. To be more specific, after receiving negative feedback, the discrepancy between $u s$ and them was significant for high self-esteem subjects in the own-groupout-group condition, $t(87)=3.68, p<.01$, but not in the ingroup-out-group condition, $t<1$, whereas this pattern tended to be reversed among those with low self-esteem, $t<1$ and $t(87)=1.94, p<.06$, respectively. Additional analyses revealed that, as before, favoritism among high self-esteem subjects was principally due to greater ratings for $u s$ in the own-group-outgroup condition than in the in-group-out-group condition, $t(87)=3.08, p<.01$. However, unlike in Study 1 , ratings for them were only slightly lower among those with low self-esteem in the in-group-out-group condition than in the own-groupout-group condition, $t<1$.

In contrast to these effects, the triple interaction was not significant among subjects receiving positive feedback, $F(1,87)=$ $1.43, n s$. Consistent with the hypothesis that positive feedback dampens self-enhancement biases, the data shown in the top half of Table 2 reveal that there was little evidence of favoritism after subjects had received positive feedback. In fact, low selfesteem subjects actually showed a reverse bias in the in-groupout-group condition following the receipt of positive feedback, giving higher ratings to the out-group's product than to the ingroup's product, $t(87)=2.48, p<.025$. One plausible explanation for this reversal is that, as self-consistency theory predicts, low self-esteem subjects had difficulty accepting feedback indicating that the in-group was superior?

Ancillary analyses. Subjects' responses on the items assessing attitudes toward the group were again highly correlated $(\alpha=$ .83 ) and were averaged to create an attraction index. An ANOVA on these scores revealed a single effect of feedback, $F(1,87)=$
Table 2

Mean Evaluation Ratings for Us and Them as a Function of Experimental Condition, Self-Esteem, and Feedback

\begin{tabular}{|c|c|c|c|c|}
\hline \multirow[b]{2}{*}{ Condition } & \multicolumn{2}{|c|}{ High self-esteem } & \multicolumn{2}{|c|}{ Low self-esteem } \\
\hline & $U s$ & Them & Us & Them \\
\hline \multicolumn{5}{|c|}{ Positive feedback } \\
\hline \multicolumn{5}{|c|}{ Own-group-Out-group } \\
\hline$M$ & 7.97 & 7.60 & 7.04 & 6.86 \\
\hline$S D$ & 1.17 & .52 & 1.42 & 1.74 \\
\hline$N$ & 7 & 57 & 16 & 31 \\
\hline \multicolumn{5}{|c|}{ In-group-Out-group } \\
\hline$M$ & 6.04 & 5.91 & 5.66 & 7.52 \\
\hline$S D$ & 1.53 & 2.26 & 2.08 & 1.29 \\
\hline$N$ & 17 & 41 & 10 & 00 \\
\hline \multicolumn{5}{|c|}{ Negative feedback } \\
\hline \multicolumn{5}{|c|}{ Own-group-Out-group } \\
\hline$M$ & 8.22 & 5.48 & 6.71 & 6.04 \\
\hline$S D$ & 1.32 & 2.38 & 1.67 & 1.39 \\
\hline$N$ & 13 & 77 & 11 & 55 \\
\hline \multicolumn{5}{|c|}{ In-group-Out-group } \\
\hline$M$ & 6.16 & 6.20 & 6.91 & 5.45 \\
\hline$S D$ & 1.88 & 1.85 & 1.38 & 1.51 \\
\hline$N$ & 10 & 40 & 11 & 82 \\
\hline
\end{tabular}

Note. Proportions of subjects showing favoritism are presented in italics.

$4.42, p<.05$, with subjects expressing more favorable attitudes toward other group members when group membership was positively valued $(M=5.36)$ than when group membership was negatively valued $(M=4.93)$. However, subjects' scores on the attraction index again did not predict favoritism.

\footnotetext{
${ }^{6}$ The classification of high and low self-esteem groups was made using the same guidelines as those used in Study 1 . This left 48 subjects classified as low in self-esteem $(M=50.31)$ and 47 subjects classified as high in self-esteem $(M=64.94)$. An analysis of variance on subjects' Texas Social Behavior Inventory scores revealed only a significant effect for self-esteem classification, $F(1,87)=172.42, p<.001$. In addition, the critical four-way interaction reported in the text remained significant when a median split on self-esteem scores was used, $F(1,103)=$ $8.70, p<.01$.

${ }^{7}$ Analyses using the mean square error for the interaction $\left(M S_{\mathrm{e}}=\right.$ 3.11) revealed the following effects: Marginal Condition $\times$ Feedback $\times$ Target interactions for those with high self-esteem, $F(1,87)=2.87, p<$ .10 , and for those with low self-esteem, $F(1,87)=3.53, p<.07$; a significant Self-Esteem $\times$ Condition $\times$ Feedback interaction for ratings for them, $F(1,87)=5.96, p<.05$, but not for ratings for us, $F(1,87)=$ 1.28 , ns; a nonsignificant Self-Esteem $\times$ Feedback $\times$ Target interaction in the own-group-out-group condition, $F(1,87)=1.56$, $n$, but a significant three-way effect in the in-group-out-group condition, $F(1$, $87)=5.41, p<.05$.

Finally, an analysis of the proportion of subjects in each condition showing favoritism revealed a significant three-way interaction, $Z=$ 2.24, $p<.025$. As shown in Table 2 , among those receiving negative feedback, a greater proportion of high self-esteem subjects showed favoritism in the own-group-out-group than in the in-group-out-group condition, whereas this pattern was reversed among low self-esteem subjects, $Z=2.25, p<.025$. This two-way interaction was not significant following the receipt of positive feedback, $Z<1$.
} 


\section{General Discussion}

The thesis underlying the present research was that all individuals strive to enhance their feelings of personal worth. However, because people with low self-esteem are more limited in their ability to directly pursue this objective than are those with high self-esteem, they are more prone to engage in indirect forms of self-enhancement. On the basis of this conception, we predicted that although individuals with high self-esteem would show group favoritism when they were directly involved in group processes, those with low self-esteem would be more apt to display favoritism when they were not directly involved in group processes.

The data supported the hypotheses. In Study 1, high self-esteem subjects exhibited favoritism when evaluating a product they had personally helped create, and did so primarily by overevaluating their own-group's product rather than devaluing the out-group's product. These findings support the contention that people with high self-esteem engage in forms of esteem enhancement that directly implicate the self. In contrast, those with low self-esteem showed little favoritism when evaluating a product they had personally helped create. Instead, they exhibited favoritism when making comparative evaluations of a product they had not helped create, and did so primarily by derogating the out-group's product. These findings support the claim that people with low self-esteem engage in forms of esteem enhancement that do not directly implicate the self.

Furthermore, in accordance with the view that these effects represent a desire to enhance self-worth, Study 2 found that these tendencies were less evident following the receipt of positive rather than negative feedback. The influence of feedback on group bias is particularly important, because it appears to support our claim that group favoritism is in service of esteem enhancement (see also Tajfel \& Turner, 1986). However, at least one other interpretation of the effects of feedback is possible. It may be argued that positive feedback dampened favoritism not because of any temporary reduction in the strength of the selfesteem motive, as we have argued, but because subjects' expectations regarding the quality of the own-group's or in-group's solution were raised so high by positive feedback that the actual solutions seemed dull in comparison.

Although this cognitively oriented explanation is plausible, two findings argue against its relevance to the present data. First, it would appear to predict a Target $\times$ Feedback interaction, rather than the four-way effect we observed. That is, it is not clear why raised expectations should systematically vary as a function of self-esteem and group involvement. Second, this account would predict that feedback would primarily affect evaluations of own-group or in-group products. However, an examination of the data in Table 2 reveals that feedback mostly affected ratings of out-group products. Across all groups, feedback had little effect on ratings for $u s, F<1$, but a considerable impact on ratings for them, $F(1,87)=9.43, p<.01$. Rather than diminishing evaluations of own-group or in-group products, then, positive feedback served primarily to enhance the appraisal of out-group products. These findings appear inconsistent with a purely cognitive account of the effects of feedback, lending greater credibility to the motivational explanation we favor.
Other research provides further evidence to support the claim that group favoritism stems from a desire to enhance self-esteem. Lemyre and Smith (1985) first categorized subjects into groups and then gave some subjects the chance to engage in group favoritism, whereas others in a control condition were given no such opportunity. Compared with those in the control condition, subjects in the experimental group subsequently showed higher levels of self-esteem. In other words, engaging in group bias was found to promote feelings of personal worth (see also Oakes \& Turner, 1980). When considered along with the effects of feedback observed in Study 2 of the present research, the finding that group discrimination enhances self-esteem gives one added confidence that the behavior of subjects in the present study does indeed stem from a desire to promote a positive self-image.

\section{Self-Enhancement, Self-Consistency, and the Nature of Self-Esteem}

At the outset of this article, it was noted that a controversy exists between self-enhancement and self-consistency theorists (see Jones, 1973; Shrauger, 1975; Swann, 1987, for reviews). Self-enhancement theorists (Jones, 1973; Kaplan, 1975) have emphasized the degree to which people actively strive to enhance feelings of personal worth. On the basis of a drive-reduction model, these theorists have proposed that people with low self-esteem seek self-aggrandizement more avidly than do those with high self-esteem, and that self-enhancement biases are therefore more prevalent among those with low self-esteem than those with high self-esteem. Self-consistency theorists, however, have emphasized the degree to which individuals actively strive to preserve their current self-conceptions (Lecky, 1945; Swann, 1987). According to this model, people with high self-esteem seek to confirm their positive self-views and those with low selfesteem, their negative self-views. The display of self-enhancement biases is thus presumed to be more prevalent among those with high self-esteem than among those with low self-esteem.

Our finding that both self-esteem groups exhibit self-enhancing biases under different conditions suggests that each of these theories may be in need of amendment. First, it seems evident that the classic self-enhancement position needs to be revised. The notion that people with negative self-concepts are more apt to display esteem-enhancing biases has consistently failed to find empirical support (see, e.g., Alloy \& Abramson, 1979; Brown, 1986; Campbell, 1986). Instead, self-enhancing illusions appear to be more characteristic of people with positive self-concepts than those with negative self-concepts (Sackeim, 1983; Taylor \& Brown, 1988). This evidence, along with the present finding that high self-esteem subjects are most prone to engage in direct self-enhancement, suggests that the self-enhancement model needs to be amended to allow for the prevalence of self-enhancing behaviors among those with high selfesteem (cf. Swann et al., 1987; Taylor \& Brown, 1988).

At the same time, our data suggest that self-consistency theory also needs to be revised. Although reluctant to engage in direct self-promotion, low self-esteem subjects exhibited indirect self-enhancement biases. A tendency to seek self-aggrandizement through indirect means suggests that those with low 
self-esteem are not disinterested in enhancing self-worth because of overriding concerns with maintaining self-consistency.

One way to account for these relations between self-esteem and self-enhancement is to assume, as we have proposed, that both individuals with high self-esteem and individuals with low self-esteem seek a positive identity, but that those with low selfesteem are more constrained in their pursuit of this goal by doubts that a favorable identity can be maintained. This analysis is conceptually similar to Shrauger's (1975) distinction between affective and cognitive responses to self-evaluative feedback. After reviewing research relevant to the self-enhancement versus self-consistency debate, Shrauger concluded that, affectively, both those with high self-esteem and those with low selfesteem desire self-enhancing feedback but, cognitively, individuals with low self-esteem are more apt to accept and believe self-confirming negative feedback.

Swann and his colleagues have recently provided evidence in support of Shrauger's (1975) affect-cognition distinction (Swann et al., 1987). These investigators first gave subjects positive or negative feedback and then measured their affective and cognitive responses. In line with Shrauger's hypothesis, affective reactions to feedback showed self-enhancement effects, with positive feedback leading to better mood among all subjects regardless of self-esteem level. Cognitive reactions to events, however, showed a self-consistency effect, with high self-esteem subjects rating favorable feedback as especially self-descriptive, and low self-esteem subjects rating unfavorable feedback as especially self-descriptive.

These findings suggest that both self-enhancement and selfconsistency processes exert an important influence on behavior. Among those with high self-esteem, these processes would appear to operate in concert to promote the use of self-enhancing biases. That is, for these individuals, the motive to enhance selfworth is not blocked by a countervailing concern with maintaining a consistent self-view. Those with low self-esteem, however, experience a conflict between self-enhancement and selfconsistency concerns (Swann et al., 1987). On the one hand, they wish to enhance feelings of personal worth, but at the same time they are driven to maintain a consistent, negative self-view. Indirectly linking the self to positive identities and outcomes may represent one mechanism whereby people with low selfesteem attempt to effect a compromise between these competing demands.

\section{References}

Alicke, M.D. (1985). Global self-evaluation as determined by the desirability and controllability of trait adjectives. Journal of Personality and Social Psychology, 49, 1621-1630.

Alloy, L. B., \& Abramson, L. Y. (1979). Judgments of contingency in depressed and nondepressed students: Sadder but wiser? Journal of Experimental Psychology: General, 108, 441-485.

Baumeister, R. F., \& Tice, D. M. (1985). Self-esteem and responses to success and failure: Subsequent performance and intrinsic motivation. Journal of Personality, 53, 450-467.

Becker, E. (1968). The structure of evil. New York: Braziller.

Brewer, M. B. (1979). In-group bias in the minimal intergroup situation: A cognitive-motivational analysis. Psychological Bulletin, 86, 307324.

Brown, J. D. (1986). Evaluations of self and others: Self-enhancement biases in social judgments. Social Cognition, 4, 353-376.
Campbell, J. D. (1986). Similarity and uniqueness: The effects of attribute type, relevance, and individual differences in self-esteem and depression. Journal of Personality and Social Psychology, 50, 281294.

Cialdini, R. B., Borden, R. J., Thorne, A., Walker, M. R., Freeman, S., \& Sloan, L. R. (1976). Basking in reflected glory: Three (football) field studies. Journal of Personality and Social Psychology, 34, 366375.

Cialdini, R. B., \& Richardson, K. D. (1980). Two indirect tactics of image management: Basking and blasting. Journal of Personality and Social Psychology, 39. 406-415.

Crocker, J., \& Schwartz, I. (1985). Prejudice and ingroup favoritism in a minimal intergroup situation: Effects of self-esteem. Personality and Social Psychology Bulletin, 11, 379-386.

Crocker, J., Thompson, L. L., McGraw, K. M., \& Ingerman, C. (1987). Downward comparison, prejudice, and evaluations of others: Effects of self-esteem and threat. Journal of Personality and Social Psychology, 52, 907-916.

Dion, K. L. (1979). Status equity, sex composition of group, and intergroup bias. Personality and Social Psychology Bulletin, 5, 240-244.

Dittes, J. E. (1959). Attractiveness of group as a function of self-esteem and acceptance by group. Journal of Abnormal and Social Psychology, 59, 77-82.

Epstein, S. (1973). The self-concept revisited: Or a theory of a theory. American Psychologist, 28, 404-416.

Gerard, H. B., \& Hoyt, M. F. (1974). Distinctiveness of social categorization and attitude toward ingroup members. Journal of Personality and Social Psychology, 29, 836-842.

Helmreich, R., \& Stapp, J. (1974). Short forms of the Texas Social Behavior Inventory (TSBI), an objective measure of self-esteem. Bulletin of the Psychonomic Society, 4, 473-475.

Jones, S. C. (1973). Self- and interpersonal evaluations: Esteem theories versus consistency theories. Psychological Bulletin, 79, 185-199.

Kaplan, H. B. (1975). The self-esteem motive. In H. B. Kaplan (Ed.), Self-attitudes and deviant behavior (pp. 10-31). Pacific Palisades, CA: Goodyear.

Langer, E. J., \& Abelson, R. P. (1972). The semantics of asking a favor: How to succeed in getting help without really dying. Journal of Personality and Social Psychology, 24, 26-32.

Lecky, P. (1945). Self-consistency: A theory of personality. New York: Island Press.

Lemyre, L., \& Smith, P. M. (1985). Intergroup discrimination and selfesteem in the minimal group paradigm. Journal of Personality and Social Psychology, 49, 660-670.

McDougall, W. (1932). The energies of men. London: Methuen.

McFarlin, D. B., \& Blascovich, J. (1981). Effects of self-esteem and performance on future affective preferences and cognitive expectations. Journal of Personality and Social Psychology, 40, 521-531.

Oakes, P. J., \& Turner, J. C. (1980). Social categorization and intergroup behavior: Does minimal intergroup discrimination make social identity more positive? European Journal of Social Psychology, 10, 295301.

Pyszczynski, T., \& Greenberg, J. (1987). Toward an integration of cognitive and motivational perspectives on social inference: A biased bypothesis-testing model. In L. Berkowitz (Ed.), Advances in experimental social psychology (Vol. 20, pp. 297-340). New York: Academic Press. Rosenberg, M. (1979). Conceiving the self. New York: Basic Books.

Sackeim, H. A. (1983). Self-deception, self-esteem, and depression: The adaptive value of lying to oneself. In J. Masling (Ed.), Empirical studies of psychoanalytical theories (Vol. 1, pp. 101-157). Hillsdale, NJ: Analytic Press.

Schlenker, B. R. (1985). Identity and self-identification. In B. R. Schlenker (Ed.), The self and social life (pp. 65-99). New York: McGraw-Hill. 
Shrauger, J. S. (1975). Responses to evaluation as a function of initial self-perceptions. Psychological Bulletin, 82, 581-596.

Smith, M. B. (1968). The self and cognitive consistency. In R. P. Abelson, E. Aronson, W. J. McGuire, T. M. Newcomb, M. J. Rosenberg, \& P. H. Tannenbaum (Eds.), Theories of cognitive consistency: $A$ sourcebook (pp. 366-372). Chicago: Rand McNally.

Snyder, C. R., Lassegard, M., \& Ford, C. E. (1986). Distancing after group success and failure: Basking in reflected glory and cutting off reflected failure. Journal of Personality and Social Psychology, 51, 382-388.

Swann, W. B., Jr. (1983). Self-verification: Bringing social reality into harmony with the self. In J. Suls \& A. G. Greenwald (Eds.), Psychological perspectives on the self(Vol. 2, pp. 33-66). Hillsdale, NJ: Erlbaum.

Swann, W. B., Jr. (1987). Identity negotiation: Where two roads meet. Journal of Personality and Social Psychology, 53, 1038-1051.

Swann, W. B., Jr., Griffin, J. J., Predmore, S. C., \& Gaines, B. (1987).
The cognitive-affective crossfire: When self-consistency confronts self-enhancement. Journal of Personality and Social Psychology, 52, 881-889.

Tajfel, H., \& Turner, J. C. (1986). The social identity theory of intergroup behavior. In S. Worchel \& W. Austin (Eds.), Psychology of intergroup relations (pp. 7-24). Chicago: Nelson-Hall.

Taylor, S. E., \& Brown, J. D. (1988). Illusion and well-being: A social psychological perspective on mental health. Psychological Bulletin, 103, 193-210.

Tesser, A., \& Campbell, J. (1982). Self-evaluation maintenance and the perception of friends and strangers. Journal of Personality, 50, 261279.

Wills, T. A. (1981). Downward comparison principles in social psychology. Psychological Bulletin, 90, 245-271.

Received July 17, 1987

Revision received December 10, 1987

Accepted January 13, 1988

\section{Editor Named for APA's Clinician's Research Digest}

The Publications and Communications Board has named George Stricker of Adelphi University's Gordon F. Derner Institute of Advanced Psychological Studies Editor of Clinician's Research Digest (CRD), which is being published by the American Psychological Association as of July 1988.

The six-page newsletter reports on research related to approaches to treatment modalities, including any systematic empirical study, as well as some coverage of child and geronotological issues. Although therapy is the main focus, key assessment and diagnostic questions as well as forensic issues are covered. $C R D$ is an easy-to-read, fact-based, findings-oriented digest of research that summarizes for practitioners relevant material from the science base of practice. Complete citations are included so that clinicians interested in more information can request the full article from the author.

Although all published material will originate with the Editor, readers of $C R D$ are invited to refer to Stricker any references or reprints of articles they find valuable. 